\title{
The role of soil chemistry and soil physics in protecting soil quality: variability of sorption and transport of cadmium as an example
}

\author{
F. A. M. de Haan, S. E. A. T. M. van der Zee and W. H. van Riemsdijk \\ Department of Soil Science and Plant Nutrition, Wageningen Agricultural Univer- \\ sity, P.O. Box 8005, NL 6700 EC Wageningen, Netherlands
}

Received 13 April 1987; accepted 6 May 1987

Key words: adsorption, cadmium, soil quality, transport, variability

\begin{abstract}
Soil has many functions in the preservation of life on earth. The prerequisite conditions for proper soil functioning may be expressed in terms of quality. Chemical quality of soil is predominantly determined by presence of compounds, and more specifically by behaviour of compounds in soil. Compound behaviour is the result of the interference of properties of the compounds and of the soil system under consideration. The interactions involved can in most cases satisfactorily be described by applying methodical rules as derived in soil chemistry and soil physics. This is elaborated with examples referring to the more or less static situation as prevailing at adsorptive equilibrium, and to the dynamic situation of compound displacement in soil. The variability of soil properties appears to be of major concern. In these exemplary treatments attention is limited to the behaviour of cadmium in soil.
\end{abstract}

\section{Introduction}

Soil provides the basis for an important part of global life as it appears to us at present. The contribution of soil in this respect becomes apparent by an analysis of soil functioning. It then becomes evident that this functioning can be characterized in general as well as in more specific terms.

As an example of the first category, the contribution of soil to global element cycling may be mentioned. In this respect, the elements carbon, nitrogen, sulphur and phosphorus are of special interest. Because of the intrinsic and essential part that is taken by soil life in such element cycling, this role of soil is commonly indicated as the ecological functioning of soil. It must be realized that soil ecology then involves the complex interplay between biological, physical and chemical reactivity of the soil system.

More specific soil functions can be paraphrazed with terms such as: 
- bearing function, notably with respect to the platform which soil provides for specific forms of life;

- food production function, both directly by the generation of food products (including fibre) for humans and animals and indirectly by the generation of animal food products which are derived from crop and fodder;

- filter function for surface water and ground water, actually indicating that the water bodies mentioned usually reflect to a certain degree the composition of soil, prior in contact with the water involved.

Proper operating of soil for the different functions mentioned requires compliance with prerequisite conditions. It is self-evident that these conditions are closely related to specific soil functions, which sometimes may imply that they are even conflicting to a certain degree.

In the Netherlands the governmental policy with respect to soil protection takes the concept of so-called multifunctionality as the principal point of departure. Although a comprehensive definition of this concept is hard to achieve it can be mentioned that the ecological functioning of soil at the one side, and the unacceptability of irreversible damage to soil at the other take key positions in the approach. For all practical purposes, a hierarchy of soil functions may be accepted with the inherent relative requirements for soil conditions.

Functioning of soil in relation to chemical soil quality requires the translation in a quantitative way of the occurrence and behaviour of compounds in soil in terms of possible effects. Among evident effects of interest are then quality of ground water and surface water, and yield and composition of crops. This makes it obvious that the effect-oriented soil quality evaluation became of growing importance in the mutual interaction between policy development, and collection and interpretation of scientific soil research data (cf. also de Haan \& van Riemsdijk, 1986; de Haan et al., 1986; de Haan, 1987).

Any quantitative interpretation of a compound's presence in soil must be based on a profound insight into the behaviour of the compound of interest in the system under consideration. Such behaviour is governed by combined effects of chemical, physical and biological processes. In this contribution chemical and physical aspects involved will be given major attention. To that purpose use can be made of methodologies and rules as developed in soil science (cf. Bolt \& Bruggenwert, 1979; Bolt, 1982), although sometimes considerable simplifications are required to attain practical applicability. In the following sections such an approach is presented with respect to the more or less static situation as prevailing in the case of adsorptive equilibrium of a compound in soil. Moreover some considerations are given pertaining to the dynamic process of compound translocation in soil. Cadmium is taken as the guide compound, because this element has received extensive attention with respect to its behaviour in soil systems. At the same time, it does deserve such extra attention as it is one of the most hazardous environmental pollutants that have to be faced at present.

Sorption of solutes in soil is often described with the Langmuir or Freundlich equations. The limitation of the applicability of these equations is usually due to the sim- 
plification implied by their use for the complex sorption process in soil. Often this process depends on a large number of varying properties of both the sorbing solid phase and of the soil solution. Besides the solute concentration in the solution important system parameters are: $\mathrm{pH}$, redox potential, solution composition and its ionic strength, and contents and types of the organic matter, clay as well as soil oxides.

Whereas often mean values are given for sorption parameters one has come to realize that in fact these parameters vary as the important system parameters vary. Hence, due to the spatial variability of soil properties such as organic carbon content, or solution composition, different sorption parameters will be found for different soil samples taken in a field or taken from different fields or soil types. In this contribution we give an indication of the variability in cadmium sorption parameters that may be found. The effects of such variation on acceptable cadmium contents in soil as well as on cadmium transport are discussed for some typical cases.

\section{Cadmium sorption}

An important variable for cadmium sorption behaviour is the cadmium solution concentration $(c)$. In the environmentally relevant concentration range, which is in the order of magnitude of $10^{-6}$ to $10^{-7} \mathrm{~mol} \mathrm{~m}^{-3}$, specific sorption is dominating, whereas at a much larger concentration range this is not the case. For cadmium sorption in the practically relevant concentration range it was shown by Chardon (1984) that the Freundlich equation gives a satisfactory description. This equation is given by:

$$
q=k c^{n}
$$

In batch experiments the parameter values $k$ and $n$ were assessed for a number of Dutch soils (Table 1). In spite of the considerable difficulties with respect to experimental accuracy a number of system parameters that were not sufficiently included in soil type differences, were varied. These parameters were ionic strength $\left(I_{0}\right)$, solid:solution ratio, electrolyte composition (including the competing heavy metals zinc, lead and copper), $\mathrm{pH}$, etc. As an example of the large differences encountered for one specific soil (No 2 of Table 1) at varied $\left(\mathrm{Cl}^{-}\right), I_{0}$, and $\left(\mathrm{Ca}^{2+}\right)$, the experimental and fitted isotherms are given in Fig. 1. The huge influence of these three system parameters on cadmium sorption is clearly demonstrated with the differences in sorption in this figure. This indicates the great care required to assess the adsorption parameters for a particular case as realistic values of the system parameters may differ between, for example, agricultural soil water and waste percolation water. Taking into account the major factors controlling cadmium sorption (Christensen, 1980; Chardon, 1984) an empirical relation was derived from Eq. 1:

$$
q=k_{1}\left(\mathrm{H}^{+}\right)^{a}\left(\mathrm{Ca}^{2+}\right)^{b} c^{n}
$$

where $a \approx-0.48$ and $b \approx-0.41$ were fairly constant for a wide range of Dutch soil 
Table 1. Properties of soils and Cd-sorption parameters (Chardon, 1984).*

\begin{tabular}{|c|c|c|c|c|c|c|c|c|}
\hline \multicolumn{2}{|c|}{ Material } & $\mathrm{pH}$ & $\mathrm{CEC}_{1}$ & $\mathrm{CEC}_{2}$ & $\begin{array}{l}\text { oc } \\
(\% \mathrm{w} / \mathrm{w})\end{array}$ & $<2 \mu \mathrm{m}$ & $\mathrm{Al}$ & $\mathrm{Fe}$ \\
\hline \multicolumn{2}{|c|}{ 1. sandy } & 4.01 & 3.6 & 6.0 & 0.9 & 5.2 & 117 & 239 \\
\hline \multicolumn{2}{|c|}{ 2. sandy } & 4.92 & 3.6 & 6.0 & 0.8 & 2.1 & 178 & 260 \\
\hline \multicolumn{2}{|c|}{ 3. sandy } & 5.19 & 4.2 & 6.8 & 0.9 & 4.9 & 125 & 203 \\
\hline \multicolumn{2}{|c|}{ 4. sandy } & 4.92 & 8.3 & 16.0 & 4.0 & 3.6 & 118 & 350 \\
\hline \multicolumn{2}{|c|}{ 5. loessial } & 4.00 & 4.2 & 9.2 & 1.6 & 5.8 & 108 & 234 \\
\hline \multicolumn{2}{|c|}{ 6. loessial } & 6.85 & - & 10.3 & 2.1 & 5.4 & 102 & 248 \\
\hline \multicolumn{2}{|c|}{ 7. peaty clay } & 4.00 & 50.3 & 56.0 & 14.3 & 21.2 & 247 & 1883 \\
\hline \multicolumn{2}{|c|}{ 8. peaty } & 4.32 & 121.4 & - & 40.5 & 0.8 & 58 & 365 \\
\hline \multicolumn{2}{|c|}{ 9. clayey } & 7.93 & - & 12.6 & 1.1 & 11.5 & 185 & 293 \\
\hline \multicolumn{2}{|c|}{ 10. clayey } & 7.73 & - & 16.4 & 1.7 & 17.9 & 73 & 401 \\
\hline \multicolumn{2}{|c|}{ 11. clayey } & 5.64 & 27.0 & 34.8 & 1.6 & 40.8 & 187 & 821 \\
\hline \multicolumn{2}{|c|}{ 12. clayey } & 7.63 & - & 34.2 & 4.9 & 14.0 & 118 & 595 \\
\hline & $\% \mathrm{CaCO}_{3}$ & $T_{0}$ & $k$ & $n$ & $k(\mathrm{Zn})$ & $n(\mathrm{Zn})$ & $k(\mathrm{Cu})$ & $n(\mathrm{Cu})$ \\
\hline 1. & 0 & 0.17 & 0.0192 & 0.8175 & 0.0251 & 0.6999 & 0.0513 & 0.4363 \\
\hline 2. & 0 & 0.35 & 0.1120 & 0.7427 & 0.1647 & 0.5298 & 0.1346 & 0.4855 \\
\hline 3. & 0 & 0.38 & 0.2043 & 0.7781 & 0.2325 & 0.6008 & 0.2899 & 0.4564 \\
\hline 4. & 0 & 0.27 & 0.2843 & 0.8273 & 0.2662 & 0.6847 & 0.4300 & 0.4687 \\
\hline 5. & 0 & 0.13 & 0.0152 & 0.8165 & 0.0111 & 0.8369 & 0.0288 & 0.5405 \\
\hline 6. & 0 & 0.21 & 1.1360 & 0.8098 & 0.7398 & 0.6778 & 1.0070 & 0.5577 \\
\hline 7. & 0 & 0.57 & 0.2322 & 0.9009 & 0.2841 & 0.7653 & 0.3130 & 0.6972 \\
\hline 8. & 0 & 0.14 & 0.8305 & 0.9137 & 0.6391 & 0.8761 & 0.7631 & 0.8097 \\
\hline 9. & 2.0 & 0.33 & 4.2580 & 0.7454 & 1.6940 & 0.4816 & 2.0340 & 0.4608 \\
\hline 10. & 10.1 & 0.50 & 3.6180 & 0.8170 & 2.2930 & 0.5769 & 2.8560 & 0.5447 \\
\hline 11. & 0 & 0.40 & 0.4186 & 0.8960 & 0.4721 & 0.7164 & 0.5039 & 0.6332 \\
\hline 12. & 3.7 & 0.52 & 4.2650 & 0.9388 & 3.1240 & 0.6553 & 4.2560 & 0.5196 \\
\hline
\end{tabular}

${ }^{*} \mathrm{pH}$ is measured in suspension, $\mathrm{CEC}_{1}$ by exchanging with $\mathrm{NH}_{4}^{+}, \mathrm{CEC}_{2}$ according to Bascomb, oc (\% w/w) according to Kurmies, $\mathrm{Fe}$ and $\mathrm{Al}$ by warming with $\mathrm{Na}_{2} \mathrm{~S}_{2} \mathrm{O}_{4}$ and complexation with oxalate followed by destruction with $\mathrm{H}_{2} \mathrm{O}_{2}$ and $\mathrm{HClO}_{4}, \% \mathrm{CaCO}_{3}$ by addition of $\mathrm{HCl} 4 \mathrm{~mol} / \mathrm{l}, T_{0}$ (cadmium initial content) by addition of $\mathrm{HCl}, \mathrm{KI}$ and anion resin. $k$ and $n$ are for the reference situation; $k(\mathrm{Zn})$ and $n$ $(\mathrm{Zn})$ are found if mass ratio $(\mathrm{Zn} / \mathrm{Cd})$ in applied solution is $100, k(\mathrm{Cu})$ and $n(\mathrm{Cu})$ if $(\mathrm{Cu} / \mathrm{Cd})=100$ in applied solution. CEC in meq $/ 100 \mathrm{~g}$ soil, Fe and $\mathrm{Al}$ in $\mathrm{mg} / 100 \mathrm{~g}$ soil, $T_{0}$ in $\mu \mathrm{g} / \mathrm{g}$; adsorption in $\mu \mathrm{g} / \mathrm{g}$ and concentration in $\mu \mathrm{g} / \mathrm{l}$ result in $k$ in $\mu \mathrm{g}^{\mathrm{l}-n} \mathrm{l}^{n} / \mathrm{g}$.

types. In order to take into account the effects of ionic strength $\left(I_{0}\right)$ and cadmium chloride complex formation the concentration in Eq. 2 should be replaced by the $\mathrm{Cd}^{2+}$ activity (Chardon, 1984). The value of $k_{1}$ varied significantly for different conditions even for one soil type. Thus for soil 2 of Table 1 , the $k_{1}$ value varied with a factor of 30 , whereas for soil 3 with a factor of 20 . Still this is a significant reduction with respect to the variation found for the same soils in the $k$ value, which was larger by orders of magnitude. This reduction is obviously due to the elimination of the effects of $\left(\mathrm{H}^{+}\right)$and $\left(\mathrm{Ca}^{2+}\right)$ in Eq. 2 as well as to the elimination of differences in soil properties as the reported variation in $k_{1}$ applies to one soil type. Whereas large differences are found for different conditions and soil types in $k$ and $k_{1}$, the value of $n$ 


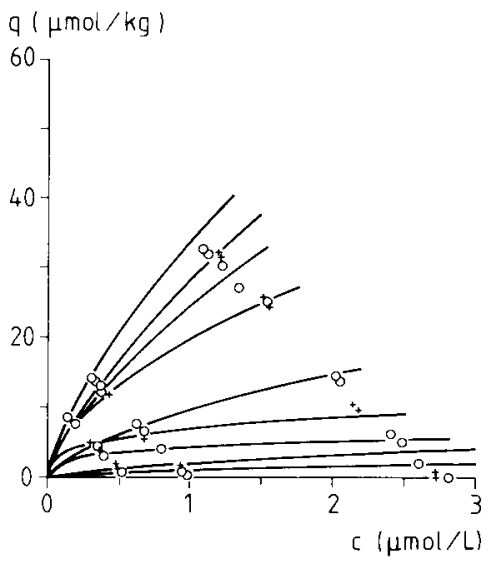

Fig. 1. Cadmium adsorption $(q)$ as a function of the concentration of cadmium in solution (c) for different values of ionic strength, chloride and calcium concentrations in solution. For details, see Chardon (1984).

exhibited in general much smaller variation and is on an average approximately 0.8 for the reference case. However, in the case of competition effects, where other heavy metals are present in a fixed ratio with cadmium the value of $n$ may be much smaller. Such an approximately constant ratio (by mass) is probably quite realistic in the environment. Taking the results of Table 1 as the point of departure, the following relation can be derived to relate sorption to the predominant sorbing phase (organic carbon, oc), and $\mathrm{pH}$ :

$$
q=k^{*} \mathrm{oc}\left(\mathrm{H}^{+}\right)^{a} c^{n}
$$

with oc as $\%(\mathrm{w} / \mathrm{w})(100 \times$ mass of organic carbon/mass of dry soil $)$ and $\left(\mathrm{H}^{+}\right)$in mol $1^{-1}$.

In Eq. 3, $a \approx-0.48$, and oc varied from 0.8 to $4.0 \%$ (w/w) (soils $1-6$, which all have a $\mathrm{pH}$ of approximately 5). The value found for $k^{*}$ is on an average $2.37 \times 10^{-5}$ if $q$ is given in $\mathrm{mol} \mathrm{kg}^{-1}$ and $c$ in $\mathrm{mol} \mathrm{m}^{-3}$. From Eqs. 2 and 3 we see that as system parameters may vary in space, this is also the case for concentrations in equilibrium with a designated total cadmium content ( $\varrho T$ on mass basis) given as

$$
\varrho T=\varrho q+\theta c
$$

This aspect is considered in the next section.

\section{Acceptable cadmium contents}

The definition of acceptable total contents in soil of contaminants should preferably be based on the relation between total content $(T)$ and soil quality. Soil quality may 
then be assessed by the relation with the functioning of soil, among others, as a living medium for soil (micro) organisms, as the growing medium of agricultural products and as a filter for percolating water. The evaluation of soil quality is thus a derivative of dose-effect relations and depends on the complex interplay between biological, physical and chemical facets of the soil system. Whereas such an evaluation is yet far from being completed this approach is rapidly growing in importance in policy development and in setting soil quality standards. Hence the collection and interpretation of soil research findings in agreement with such an approach is well on its way and leads to conflicts between scientific insights and the standards set with respect to acceptable contents of contaminants in soil that are not based on such insights.

Thus, with Eq. 4 in combination with Eq. 1 acceptable total cadmium contents in soil may be calculated for different commonly accepted standards for cadmium concentration in ground water and surface water. In illustration, the following standards were considered (in the units commonly used in this context):

- the Dutch standard for surface water to be used for preparation of drinking water: $1.5 \mu \mathrm{g} \mathrm{l}^{-1}$

- the Dutch advisory value for surface water: $2.5 \mu \mathrm{g} \mathrm{l}^{-1}$

- the EC standard for drinking water: $5.0 \mu \mathrm{g} \mathrm{l}^{-1}$

- the FAO and WHO standards for drinking water: $10.0 \mu \mathrm{g} \mathrm{l}^{-1}$

In Table 2 the total contents in equilibrium with these concentrations are given for the different $k$ values derived from the work by Chardon (1984). A pronounced variation in acceptable total cadmium contents results. The contents given in Table 2 may be evaluated with reference to the common total cadmium content found for Dutch agricultural topsoils, which is $T \leqslant 0.3 \mathrm{mg} \mathrm{kg}^{-1}$. A soil with a total content exceeding $1 \mathrm{mg} \mathrm{kg}^{-1}$ is considered as heavily contaminated.

The heavy metal content of Dutch topsoils originating from nature reserves and from agricultural land was assessed by Lexmond \& Edelman (1987). Since their analysis was directed towards the study of background levels for areas that may be considered as (at least) 'not heavily polluted', the clay content was considered to dominate the original heavy metal content (for details reference is made to the orig-

Table 2. Acceptable cadmium contents of soil, in $\mathrm{mg} / \mathrm{kg}$, for different criteria for the cadmium concentration in soil solution, in $\mu \mathrm{g} / \mathrm{l}$, for varying values of $k$ (in $\left.\mu \mathrm{g}^{1-n} \mathrm{l}^{n} \mathrm{~g}^{-1}\right)$ and $n=0.8$.

\begin{tabular}{lllcc}
\hline$k$ & \multicolumn{1}{l}{$C$} & & \\
\cline { 2 - 4 } & $1.5 \mu \mathrm{g} / \mathrm{l}$ & $2.5 \mu \mathrm{g} / 1$ & $5 \mu \mathrm{g} / \mathrm{l}$ & $10 \mu \mathrm{g} / \mathrm{l}$ \\
0.001 & 0.001 & 0.002 & 0.004 & 0.006 \\
0.01 & 0.01 & 0.02 & 0.04 & 0.06 \\
0.1 & 0.1 & 0.2 & 0.4 & 0.4 \\
0.3 & 0.4 & 0.6 & 1.1 & 1.9 \\
0.5 & 0.7 & 1.0 & 1.8 & 3.2 \\
0.9 & 1.2 & 1.9 & 3.3 & 5.7 \\
6 & 8.3 & 12.5 & 21.7 & 37.9 \\
\hline
\end{tabular}




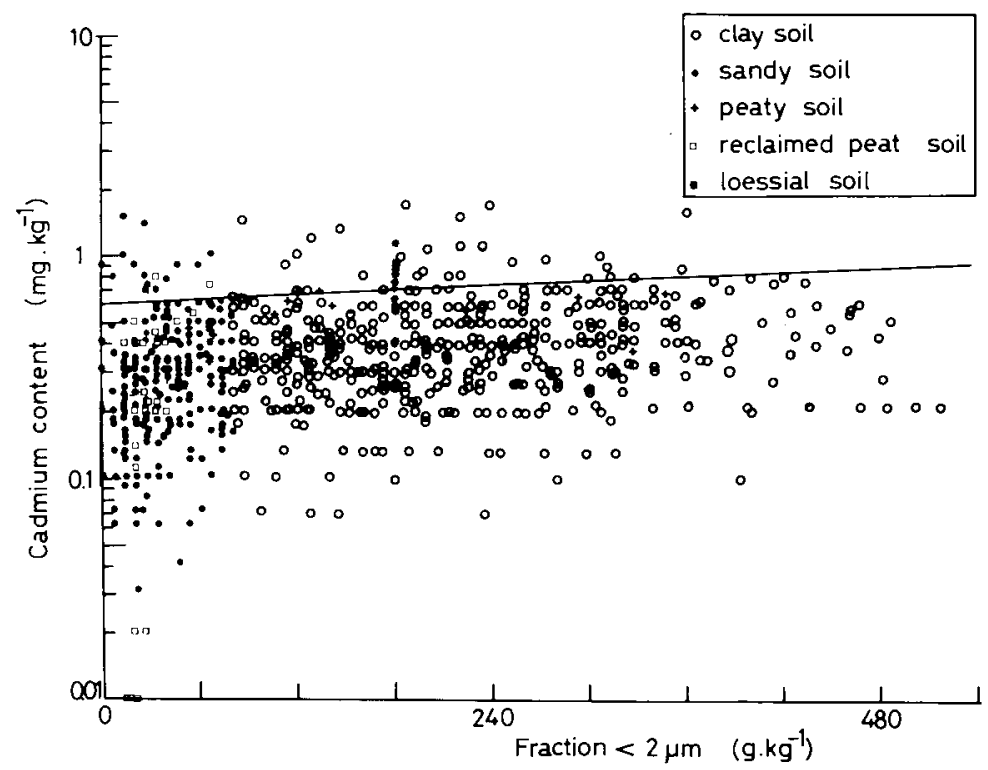

Fig. 2. Cadmium content of topsoil samples of about 970 fields in agricultural use, as a function of the fraction $<2 \mu \mathrm{m}$, according to data compiled by the Institute for Soil Fertility, Haren, Netherlands. The line indicates the upper limit of values found in the top $10 \mathrm{~cm}$ of soil in Dutch nature reserves.

inal report). Since the anthropogenic contribution to cadmium contamination of soil is predominantly due to the cadmium immission from air and the use of phosphate fertilizers on agricultural land, the cadmium data were treated just as the data of other metals. This results in the total cadmium contents as a function of the clay contents shown in Fig. 2 for samples from 970 fields in agricultural use on 5 different soil types. The full line represents the upper level found in nature reserve areas which appears to be exceeded only in a few cases. Although a complete comparison is not possible due to the sometimes differing sampling depths it is nevertheless appropriate to assume that the situation on agricultural land and on natural reserve areas is not considerably different. Moreover, we conclude that significant differences occur in the immission of cadmium for different fields, on the basis of the observed differences in the total content. Hence both the sorption constant, $k$ (or $k_{1}$, $k^{*}$ ) and the total content, $T$, are spatially variable properties. This implies that also the cadmium concentration in solution must be a spatially variable property. Due to the key position of $c$ with respect to compound (here cadmium) mobility we therefore conclude that the concentration-controlled processes of accumulation, plant uptake, and leaching are spatially variable processes (van der Zee et al., 1987). In illustration, in the next section the framework is given to cope with the spatial variability of the leaching process. 


\section{Cadmium transport in heterogeneous soil systems}

Cadmium transport through a column in the vertical downward direction $(z)$ may be described wit the equation

$$
\frac{\partial}{\partial t}[\varrho q]+\frac{\partial}{\partial t}[\theta c]=\frac{\partial}{\partial z}\left[\theta D \frac{\partial c}{\partial z}\right]-\frac{\partial}{\partial z}[v \theta c]
$$

where $q$ is given by Eqs. 1,2, or 3. In the general case of a physically or chemically non-homogeneous soil column or in case of transient water-flow, Eq. 5 is usually solved numerically for the appropriate initial and boundary conditions. In practice it may be hard to condition transport experiments in physically homogeneous, packed columns such that homogeneity in a soil chemical sense is also ascertained. If the feed solution is not in equilibrium with the solid phase with respect to the main solutes present, gradients are imposed in the soil solution for the main solutes as well as for the compound studied (cadmium). Thus, if gradients are imposed in the direction of $z$ with respect to, for example, the $\mathrm{pH}$ or $\left(\mathrm{Ca}^{2+}\right)$, then the propagation velocity of the cadmium front becomes dependent on the depth $z$. This propagation velocity $\left(v_{\mathrm{Cd}}\right)$ is given by

$$
v_{\mathrm{Cd}}=v /\left\{1+\varrho k\left(c_{0}^{n}-c_{i}^{n}\right) /\left[\theta\left(c_{0}-c_{i}\right)\right]\right\}=v / R
$$

if the Freundlich equation (Eq. 1) applies. Clearly through the dependence of $k$ on, for example, the spatially (in $z$ ) varying $\mathrm{pH}$ or $\left(\mathrm{Ca}^{2+}\right)$ also $v_{\mathrm{Cd}}$ becomes dependent on $z$. If such effects are significant, multicomponent transport models are required to describe transport (Jennings et al., 1982; Sardin et al., 1986; Förstner, 1986).

For simplicity, we assume that transport of cadmium occurs through a sufficiently homogeneous soil column in the field. Furthermore the slight non-linearity of the sorption isotherm is neglected by setting $n$ equal to unity. Then Eq. 5 may be solved analytically for the conditions:

$$
\begin{array}{lll}
c_{i}=0 & 0 \leqslant z \leqslant \infty & t=0 \\
c-\frac{D}{v} \frac{\partial c}{\partial z}=c_{0} & z=0 & t \geqslant 0 \\
\frac{\partial c}{\partial z}=\text { finite } & z \rightarrow \infty & t \geqslant 0
\end{array}
$$

The solution is given by (van Genuchten, 1981):

$$
\begin{aligned}
c(z t) / c_{0}= & 1 / 2 \operatorname{erfc}\left[\frac{R z-v t}{2(D R t)^{1 / 2}}\right]+\left(\frac{v^{2} t}{\pi D R}\right)^{1 / 2} \exp \left[-(R z-v t)^{2} /(4 D R t)\right] \\
& -1 / 2\left(1+\frac{v z}{D}+\frac{v^{2} t}{D R}\right) \exp \left(\frac{v z}{D}\right) \operatorname{erfc}\left[\frac{R z+v t}{2(D R t)^{1 / 2}}\right]
\end{aligned}
$$




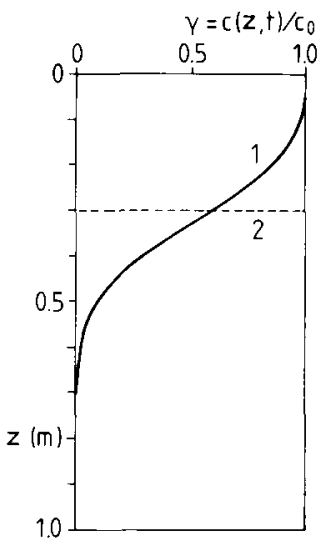

Fig. 3. Dimensionless concentration $\left(\gamma=c / c_{0}\right)$ as a function of depth (z) calculated with field averaged parameter values of Table 3. Curve 1 according to Eq. 9, and curve 2 according to Eq. 10 .

Table 3. Parameter values used in the transport calculations.

\begin{tabular}{llll}
\hline Variable & Value & Variable & Value \\
$v$ & & & \\
$\theta$ & $1.0 \mathrm{~m} \mathrm{year}^{-1}$ & $k^{* 1}$ & $2.37 \times 10^{-5}$ \\
$D$ & 0.3 & $\mathrm{pH}^{1}$ & 5.25 \\
$\varrho$ & $0.03 \mathrm{~m}^{2} \mathrm{year}^{-1}$ & $\mathrm{oc}^{1}$ & $2.31 \%(\mathrm{w} / \mathrm{w})$ \\
$L$ & $1400 \mathrm{~kg} \mathrm{~m}^{-3}$ & $c_{\mathrm{i}}$ & $0 \mathrm{~mol} \mathrm{~m}^{-3}$ \\
$t$ & $1 \mathrm{~m}$ & $c_{0}$ & $5.0 \times 10^{-5} \mathrm{~mol} \mathrm{~m}^{-3}$ \\
\hline
\end{tabular}

1 Values for Fig. 3 only.

where $R$ is the denominator of Eq. 6. The cadmium profile in solution is shown in Fig. 3 (curve 1) for $t=106$ years and the parameter values of Table 3 . It is noted that a slightly steeper profile would have been found if the adsorption isotherm were not linearized (i.e., $n \approx 0.8$ ) (van der Zee \& van Riemsdijk, 1987).

Thus, if the parameter values of Table 3 were average values for a number of samples derived from a field one might be tempted to conclude that Fig. 3 (curve 1) represents the cadmium profile in the field. This, however, is in general not true for reasons given by Dagan \& Bresler (1979), van der Zee \& van Riemsdijk (1986) and de Haan et al. (1986), and we will illustrate why this is not the case, for a particular situation. As indicated before, the propagation velocity of the cadmium front depends, among others, on $v$ and $k$ (Eq. 6). Both variables will differ for different columns sampled in a field. Even if the (well-documented) spatial variability in soil hydraulic properties (and $v$ ) is neglected, the spatial variability in $k$ caused by the heterogeneity of the field with respect to, for example, $\%$ oc and $\mathrm{pH}$ may have a profound effect on the cadmium profile in the field. If we disregard pore scale dispersion Eq. 9 simplifies to

$$
c(\zeta, t) / c_{0}=\gamma=H\left(\frac{v t}{R L}-\zeta\right)
$$


where $L$ is the total depth considered (e.g. till freatic water), $\zeta=z / L$ is the dimensionless depth, and the 'heaviside step function' $H(\varepsilon)=1$ for $\varepsilon \geqslant 0$ and $H(\varepsilon)=0$ for $\varepsilon<0$. This profile is also shown in Fig. 3 (curve 2).

Let us assume that all variables and parameters have the values of Table 3 and that $\mathrm{pH}$ and oc are spatially variable (stochastic) properties, which are characterized with a probability density function (PDF) with particular expectation values and variances. Then an expression for the relative concentration $(\gamma)$ averaged for the whole field at depth $\zeta$ and time $t$ may be derived similar to the case of van der Zee \& van Riemsdijk (1986). The details of this derivation are given by van der Zee \& van Riemsdijk (1987) and are omitted here, for brevity. The result for the field averaged concentration, $\langle\gamma\rangle$, is

$$
<\gamma(\zeta, t)>=1 / 2\left\{1-\operatorname{erf}\left[\frac{\ln (\zeta)-\mathrm{m}(\underline{Y})}{s(\underline{Y}) \sqrt{ } 2}\right]\right\}
$$

where $\underline{Y}=\ln (Y)$ and the dimensionless front penetration depth $(Y)$ is

$$
Y=v t /(R L)
$$

In Eq. 11 the arithmetic mean and the standard deviation of $\underline{Y}$ are $m(\underline{Y})$ and $s(\underline{Y})$, respectively, and these statistics follow from the statistics of $\mathrm{pH}$ and oc as discussed by van der Zee \& van Riemsdijk (1987).

With Eq. 11 the field averaged cadmium profile may be calculated for varying values of $\xi$ between 0 and 1 . Some results are given in Fig. 4 . If the variances of both $\mathrm{pH}$ and oc are set equal to zero a unique value of $k$ and therefore also a unique $R$ value is found and the cadmium step profile is identical to the cadmium profile if pore scale dispersion is neglected, in Fig. 3. The other cadmium profiles shown in Fig. 4 are, however, completely different. These profiles were obtained from the distributions of $\mathrm{pH}$ and oc given in Table 4 . Thus curve 1 represents the situation if variability is relatively small for both $\mathrm{pH}$ and oc and is considered representative for

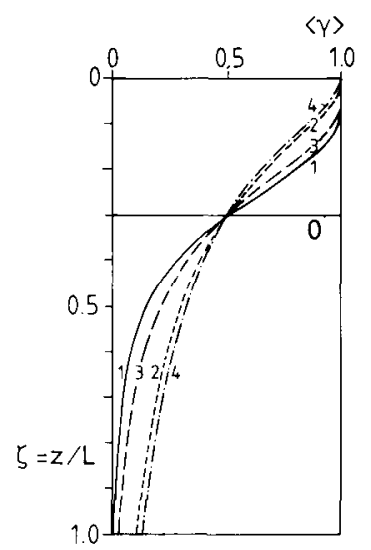

Fig. 4. Field averaged dimensionless concentration $(\langle\gamma\rangle)$ as a function of dimensionless depth $(\zeta=z / L)$, calculated assuming that $\mathrm{pH}$ and oc are stochastic variables. Numbers on the curves refer to Table 4. 
Table 4. Probability density functions (PDF) assumed for $\mathrm{pH}$, oc and $R$. Normal PDF: $N\left(m ; s^{2}\right)$, and lognormal PDF: $\Lambda\left(m ; s^{2}\right)$, with $m=$ expectation, and $s^{2}=$ variance, which in case of oc and $R$ apply to the lognormally transformed data.

\begin{tabular}{llllll}
\hline Variable & \multicolumn{5}{l}{ Curve (see Fig. 4) } \\
\cline { 2 - 6 } & 0 & 1 & 2 & 3 & 4 \\
& & & & & \\
$\mathrm{pH}$ & $N(5.25 ; 0.0)$ & $N(5.25 ; 0.16)$ & $N(5.25 ; 0.74)$ & $N(5.25 ; 0.16)$ & $N(5.25 ; 0.74)$ \\
$\mathrm{oc}$ & $\Lambda(0.84 ; 0.0)$ & $\Lambda(0.84 ; 0.04)$ & $\Lambda(0.84 ; 0.04)$ & $\Lambda(0.84 ; 0.16)$ & $\Lambda(0.84 ; 0.16)$ \\
$R$ & $\Lambda(5.87 ; 0.0)$ & $\Lambda(5.87 ; 0.25)$ & $\Lambda(5.87 ; 0.96)$ & $\Lambda(5.87 ; 0.40)$ & $\Lambda(5.87 ; 1.16)$ \\
\hline
\end{tabular}

variations found in a single field. For curve 2 the variance of $\mathrm{pH}$, and for curve 3 the variance of oc, were increased to the values derived from data of Lexmond et al. (1982). Van der Zee \& van Riemsdijk (1987) showed that indeed pH was normally distributed and oc was lognormally distributed for the 84 different Dutch topsoil samples of Lexmond et al. (1982). For curve 4 both oc and $\mathrm{pH}$ were distributed according to the distributions found for these 84 topsoil samples.

Comparing Figs. 3 and 4 the profound differences in the profiles are clear. Whereas Eq. 8 leads to a sigmoid profile, in Fig. 4 non-sigmoid curves were obtained. If the spatial variability in $k$ is taken into account the moment of first breakthrough at the reference level $z=L$ occurs much sooner than estimated with fieldaveraged parameter values. Thus, if $\langle\gamma(z, t)\rangle=0.01$ the concentration at $z=L$ for the whole field will on average be $0.01 c_{0}$, and clearly this moment occurs sooner for the situations depicted in Fig. 4, even though pore scale dispersion is completely neglected! If $\mathrm{pH}$ and oc are not independent stochastic variables, as well as when heterogeneity of the field with respect to, for example, cadmium immission, clay content, or flow velocity $(v)$ are taken into consideration the effects may be even more prominent (van der Zee \& van Riemsdijk, 1987).

\section{Conclusions}

In this paper the effect of variability of cadmium sorption parameters on permissible total cadmium contents in soil and on cadmium transport was considered. Based on the work by Chardon (1984) sorption was described with the Freundlich equation. In this work the effects of solution composition parameters and solid phase composition on the Freundlich coefficient $(k)$ were made explicit. Due to the huge variation in $k$ occurring for different soil types a wide range in the total cadmium content results if commonly accepted standards for cadmium concentration in solution are applied. In view of the apparent differences in vulnerability with respect to adverse effects on soil quality for the different soil types studied by Chardon (1984) it is clear that in setting standards for total contents in cadmium, as well as other heavy metals, one should take such differences into account.

The variation in $k$ will also have a profound effect on transport. Thus, if breakthrough of cadmium at a reference plane such as the freatic groundwater level is of interest it is in general not correct to represent a field by a single column with aver- 
aged parameter values. If this is done nevertheless first cadmium breakthrough is estimated to occur much later than may happen in reality. This was demonstrated by assuming that only the retardation factor $(R)$ is a stochastic variable, due to the variability of the Freundlich coefficient $(k)$. In practice the effect of soil heterogeneity may be much more pronounced if the variability in other properties is also taken into account.

Due to the key position of the concentration of contaminants with respect to plant uptake and transport (de Haan \& van Riemsdijk, 1986; van der Zee et al., 1987) the stochastic nature of sorption is of significant importance. Since the quality of both agricultural crops and of the percolation water feeding groundwater depends on the composition of the soil solution the stochasticity of sorption implies that also the vulnerability of soil for pollution is of a stochastic nature. This aspect, that has received relatively little attention in the past, deserves emphasis in soil pollution and soil protection research in the future.

\section{Abbreviations}

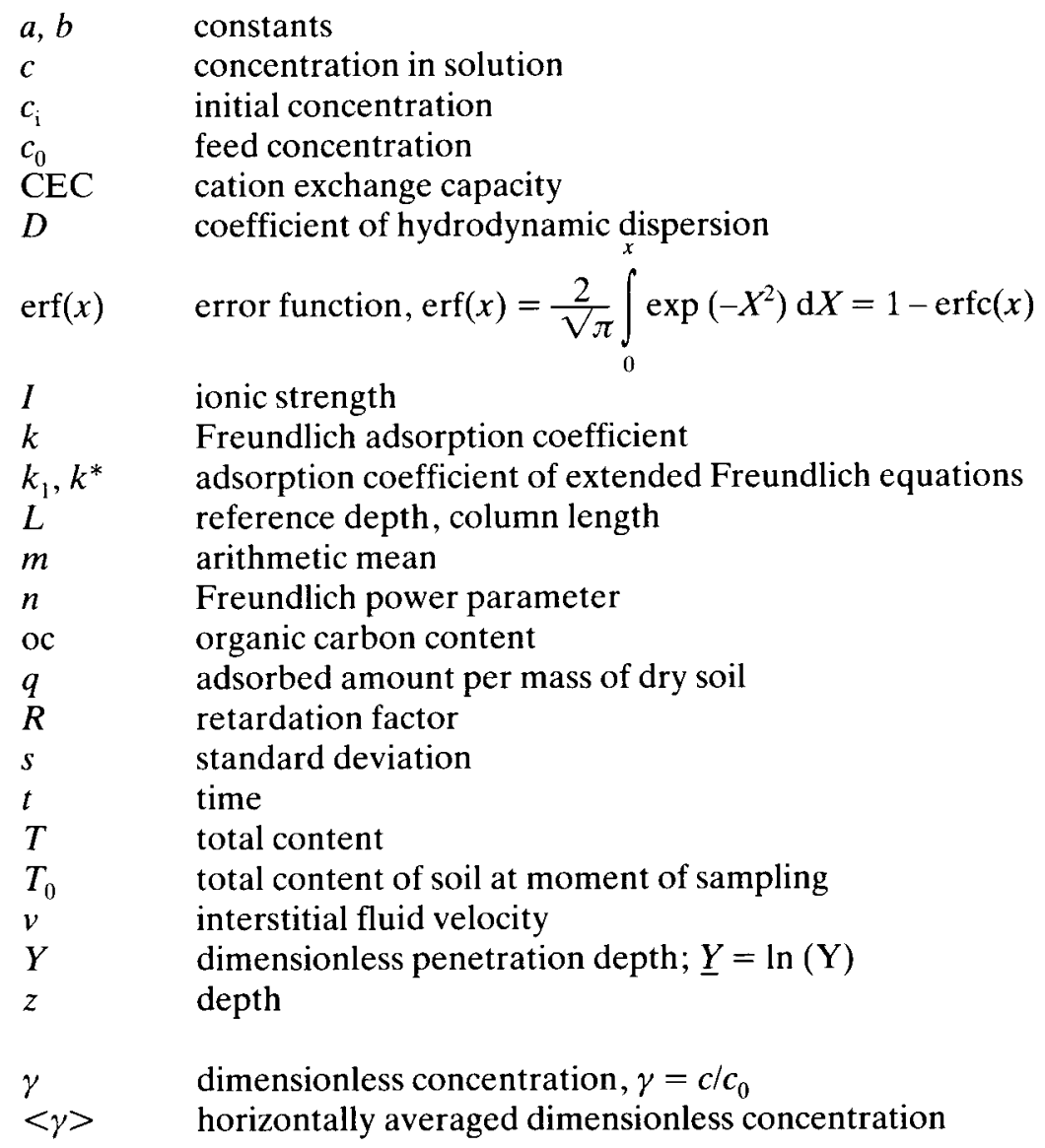




$\begin{array}{ll}\varrho & \text { dry bulk density } \\ \theta & \text { volume fraction of liquid } \\ \zeta & \text { dimensionless depth } \zeta=z / L\end{array}$

\section{References}

Bolt. G. H. (Ed.). 1982. Soil chemistry. B. Physico-chemical models, 2nd ed. Elsevier. Amsterdam, 479 pp.

Bolt. G. H. \& M. G. Bruggenwert (Eds.), 1979. Soil chemistry. A. Basic elements, 3rd ed. Elsevier, Amsterdam. $281 \mathrm{pp}$.

Chardon. W. J., 1984. Mobility of cadmium in soil. (In Dutch.) Doctoral thesis, Wageningen Agricultural University. Scrie Bodembescherming No 36. Staatsuitgeverij, 's-Gravenhage, 200 pp.

Christensen, T. H., 1980. Cadmium sorption onto two mineral soils. Department of Sanitary Engineering, Technical University Denmark, Lingby, $352 \mathrm{pp}$.

Dagan, G. \& E. Bresler, 1979. Solute dispersion in unsaturated soil and field scale. I. Theory. Soil Science Society of America Journal 43: 461-467.

Förstner, R., 1986. A multicomponent transport model. Geoderma 38: 261-278.

Haan. F. A. M. de. 1987. Soil quality in relation to soil functions. In: W. van Duivenbooden \& H. G. van Waegeningh (Eds.). Vulnerability of Soil and Groundwater to Pollutants. p. 59-68. Proceedings and Information No 38 . CHO-TNO, The Hague.

Haan, F. A. M. de, M. G. Keizer, Th. M. Lexmond, W. H. van Riemsdijk \& S. E. A. T. M. van der Zee, 1986. Some recent developments and approaches in soil protection research. Netherlands Journal of Agricultural Science 34: 361-370.

Haan, F. A. M. de \& W. H. van Riemsdijk, 1986. Behaviour of inorganic contaminants in soil. In: J. W. Assink \& W. J. van den Brink (Eds.), Contaminated soil, p. 19-32. Martinus Nijhoff, Dordrecht.

Jennings, A. A., D. J. Kirkner \& T. L. Theis, 1982. Multicomponent equilibrium chemistry in ground water quality models. Water Resources Research 18: 1089-1096.

Lexmond, Th. M., W. H. van Riemsdijk \& F. A. M. de Haan, 1982. A study of phosphate and copper in soil, especially in areas with intensive animal husbandry. (In Dutch.) Serie Bodembescherming No 9, $159 \mathrm{pp}$. Staatsuitgeverij, 's-Gravenhage.

Lexmond, Th. M. \& Th. Edelman, 1987. Current background values of a number of heavy metals and arsenic in soil. (In Dutch). In: Handboek voor milieubeheer, Vol. IV: Bodembescherming, Chap. D4110, 32 pp. Samsom, Alphen aan den Rijn.

Sardin, M., R. Krebs \& D. Schweich, 1986. Transient masstransport in the presence of non-linear physico-chemical interaction laws: progressive modelling and appropriate experimental procedures. Geoderma 38: 115-130.

Van Genuchten, M. Th., 1981. Analytical solutions for chemical transport with simultaneous adsorption, zero-order production and first-order decay. Journal of Hydrology 49: 213-233.

Zee, S. E. A. T. M. van der. W. H. van Riemsdijk. Th. M. Lexmond \& F. A. M. de Haan, 1987. Vulnerability in relation to physico-chemical compound behaviour, and spatially variable soil properties. In: W. van Duivenbooden \& H. G. van Waegeningh (Eds.), Vulnerability of Soil and Groundwater to Pollutants, p. 515-526. Proceedings and Information No 38. CHO-TNO, The Hague.

Zee, S. E. A. T. M. van der \& W. H. van Riemsdijk, 1986. Transport of phosphate in a heterogeneous field. Transport in Porous Media 1: 339-359.

Zee, S. E. A. T. M. van der \& W. H. van Riemsdijk, 1987. Transport of reactive solute in a spatially variable system. Water Resources Research 23 (in press). 